\title{
Uso de software libre y de código abierto para la identificación de lineamientos estructurales y realce de estructuras geológicas
}

\author{
Use of free and open-source software to identify structural lineaments and \\ enhancement of geological structures
}

\author{
Yessenia Puma Enriquez",a, Wilson López Abanto ${ }^{2, b}$, Yenifer Mamani Laura ${ }^{1, c}$, Diana Lozano Flores ${ }^{1, d}$, \\ Johan Angel Nuñez Muñoz ${ }^{1, e}$
}

Recibido: 16/05/2021 - Aprobado: 04/10/2021 - Publicado: 23/12/2021

\begin{abstract}
RESUMEN
El objetivo principal de este estudio consiste en el uso de software libre y de código abierto para identificar lineamientos estructurales y el realce de estructuras geológicas, sin la necesidad de usar softwares comerciales. En este estudio se utilizó un modelo de elevación digital (DEM) con una resolución de $12.5 \mathrm{~m}$ ALOS PALSAR, sobre el cual se aplicaron distintas técnicas de visualización de relieve obteniendo lineamientos estructurales y realce de estructuras geológicas (posibles fallas), además se realizaron gráficos de rosetas e histogramas, con ayuda de software libre y de código abierto como son QGIS 3.4.12, SAGA GIS, Stereonet y OpenStereo. Los lineamientos se analizaron mediante la frecuencia de azimut, usando diferentes métodos; Sombreamiento multidireccional, Sombreamiento con variación de luz cada $30^{\circ}$, Sombras combinadas, Mapa de Imagen de Relieve Rojo; y finalmente se realizó la obtención y procesamiento de lineamientos estructurales con cada técnica de visualización, se obtuvieron 745 con la técnica de sombreamiento multidireccional, 1173 por sombreamiento con variación de luz cada $30^{\circ}, 736$ y 749 por las sombras combinadas 1 y 2 respectivamente y 139 estructuras geológicas que representan fallas inferidas con la técnica de Mapa de Imagen de Relieve Rojo (RRIM); los cuales indican una tendencia en dirección andina NW-SE. Para complementar la interpretación se generaron gráficos de rosetas e histogramas para cada tipo de método, que al compararlas se encontraron 6 tendencias generales; se observa que las tendencias obtenidas en los diferentes procesos presentan similitud con la dirección de las fallas regionales presentes en la zona de estudio. Se concluye que las técnicas utilizadas son fiables, útiles y complementarias entre sí, para reconocer, analizar, determinar e interpretar lineamientos estructurales en una etapa de pre-campo con ayuda de Software libre y de código abierto.
\end{abstract}

Palabras claves: Estructuras; lineamientos; sombreamiento; fallas; rosetas; histogramas.

\begin{abstract}
This main objective of this study is the use of free and open source software to identify structural lineaments and enhancement of geological structures, without the need to use commercial software. In this study, a digital elevation model (DEM) with a resolution of $12.5 \mathrm{~m}$ ALOS PALSAR was used on which the different relief visualization techniques were performed, obtaining structural guidelines and enhancement of geological structures (possible faults), in addition graphs were made of rosettes and histograms, with the help of free and open source software such as SAGA GIS, QGIS 3.4.12, Stereonet and OpenStereo. The lineaments were analyzed by azimuth frequency, using different methods; Multidirectional shading, Shading with light variation every $30^{\circ}$, Combined shadows, Red Relief Image Map (RRIM); and finally the obtaining and processing of structural guidelines was carried out with each visualization technique, 745 were obtained with the multidirectional shading technique, 1173 by shading with light variation every $30^{\circ}, 736$ and 749 by the combined shadows 1 and 2 respectively and 139 geological structures representing faults inferred with the Red Relief Image Map (RRIM) technique; which indicate a trend in an Andean NW-SE direction. To complement the interpretation, rosette graphs and histograms were generated for each type of method, which when comparing them, 6 general trends were found; it is observed that the tendencies obtained in the different processes present similarity with the direction of the regional faults present in the study area. It is concluded that the techniques used are reliable, useful and complementary to each other to recognize, analyze, determine and interpret structural guidelines in a pre-field stage with the help of free and open source software.
\end{abstract}

Keywords: Structures; guidelines; shading; faults; rosettes; histograms.

\footnotetext{
1 Universidad Nacional de San Antonio Abad del Cusco, Cusco, Perú.

2 Universidade de Brasília, Instituto de Geociências, Brasília, Brasil.

a Autor para correspondencia: 170401@unsaac.edu.pe - ORCID: https://orcid.org/0000-0002-3522-4157

b E-mail: wilsonlopezgeo@gmail.com - ORCID: https://orcid.org/0000-0002-3673-671X

c E-mail: yeni.geologia.g17@gmail.com - ORCID: https://orcid.org/0000-0002-2348-1965

d E-mail: 171251@unsaac.edu.pe - ORCID: https://orcid.org/0000-0003-0763-3292

e E-mail:133808@unsaac.edu.pe
} 


\section{INTRODUCCIÓN}

Existen varias técnicas de visualización de relieve mediante el uso de herramientas SIG de código abierto, a partir de un modelo de elevación digital (DEM), que son rápidos de implementar y que se pueden usar para múltiples propósitos; y en este trabajo nos hemos basado en las técnicas propuestas por (TZVETKOV JORDAN, 1978) para determinar lineamientos estructurales y realce de estructuras geológicas (posibles fallas). Además, para trabajar con los datos de las direcciones obtenidos en estos procesos hemos hecho uso de los softwares Stereonet (Allmendinger et al., 2012) y OpenStereo (Grohmann et al., 2011). (Mader \& Schenk, 2017) resaltan el uso de los softwares libres y de código abierto; y el motivo principal de usar estos softwares (Tabla 1) se basa en que no genera ningún costo y se pueden realizar los mismos procesos que los softwares comerciales.

Un lineamiento estructural es definido por (O'Leary et al., 1976) como un elemento lineal, cartografiable, simple o compuesto de una superficie, cuyas partes están alineadas en una relación rectilínea o ligeramente curvilínea, la cual difiere distintivamente de patrones de elementos adyacentes y presumiblemente refleja un fenómeno bajo la superficie. Teniendo en cuenta la definición de los lineamientos estructurales y las técnicas usadas en este artículo, son trabajos que se realizan en una etapa de pre-campo para generar posibles interpretaciones estructurales y luego comprobarlos en campo (Bruno de Olivera et al., 2009). En la zona de estudio (Figura 1) se tiene fallas reconocidas por el Servicio Geológico de Perú, INGEMMET (Instituto
Geológico, Minero y Metalúrgico), las cuales nos servirán como control de calidad.

Teniendo en cuenta todo lo mencionado, el objetivo de este artículo es fomentar el uso de software libre y de código abierto para replicar estas técnicas en la identificación de lineamientos estructurales y realce de estructuras geológicas, así como hacer una correlación de las diferentes técnicas de realce de relieve con los datos obtenidos de INGEMMET (Carlotto Caillaux et al., 1996), (Carlotto Caillaux et al., 2011) para su validación.

Tabla 1. Softwares usados (si: S y no: N)

\begin{tabular}{lcc}
\hline Software & Libre & Código Abierto \\
\hline QGIS & $\mathrm{S}$ & $\mathrm{S}$ \\
SAGA GIS & $\mathrm{S}$ & $\mathrm{S}$ \\
STEREONET & $\mathrm{S}$ & $\mathrm{N}$ \\
OPENSTEREO & $\mathrm{S}$ & $\mathrm{S}$ \\
\hline
\end{tabular}

\subsection{Ubicación de la zona de estudio}

La zona de estudio se ubica al sur del Perú en el departamento de Cusco y abarca las provincias de Cusco, Urubamba, Anta, Paruro y Calca (Figura 1).

\subsection{Configuración Geológica}

En la zona de estudio, el sistema estructural sigue una dirección preferente, de este modo presenta fallas con dirección andina NW-SE de tipo normal, inversa y de rumbo, algunas de estas son reconocidas como fallas regionales (Carlotto et al., 2011). Así también se tienen fallas activas

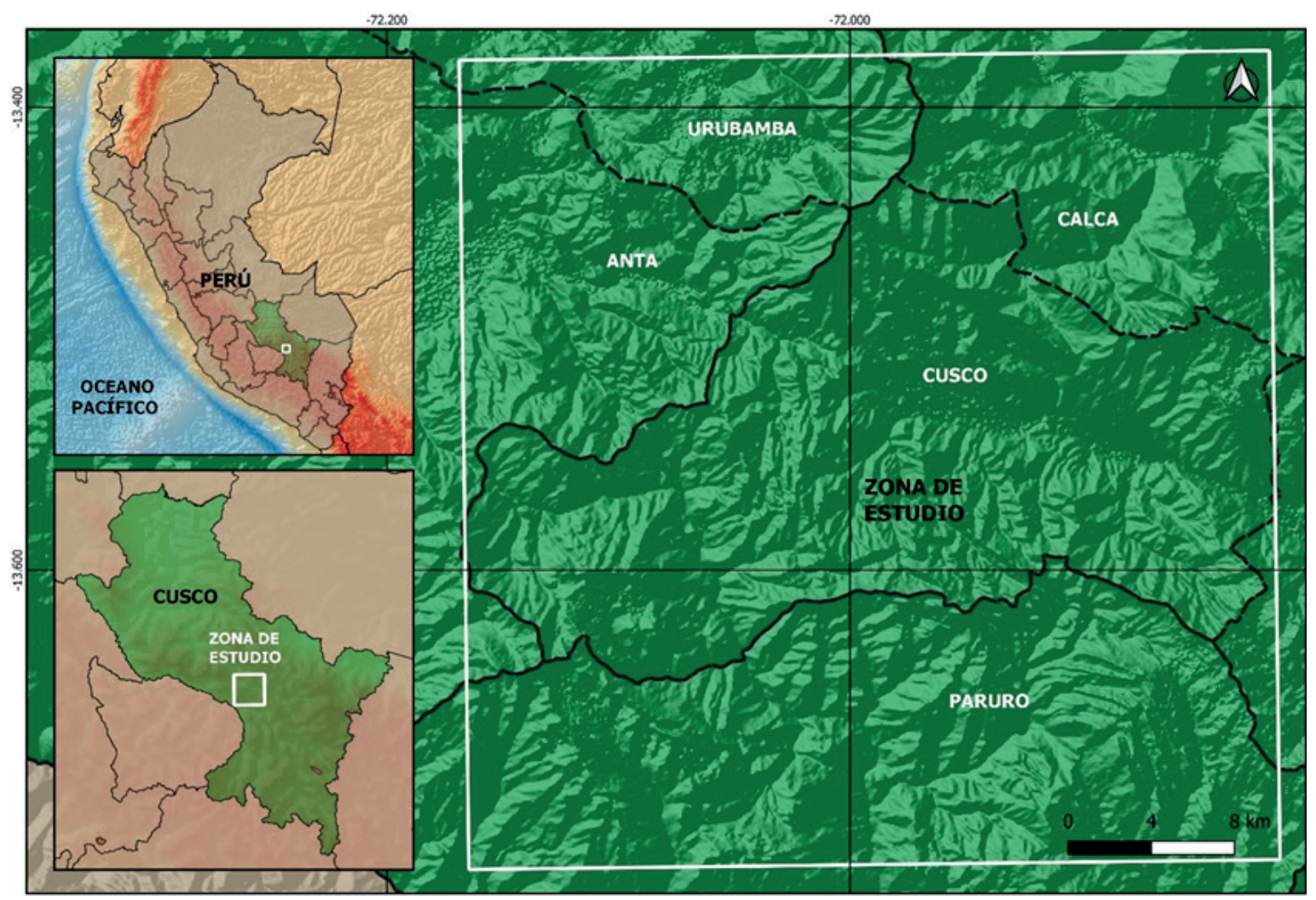

Figura 1. Mapa de Ubicación de la zona de estudio en el departamento de Cusco. 
como Tambomachay, Tamboray, Qoricocha, Pachatusan y Cusco, que han sido controladas por la evolución tectónica y sedimentaria pliocuaternaria (Cabrera Nuñez Justo, 1988); (Benavente et al., 2013).

Las fallas regionales importantes (Figura 2) en nuestra zona de estudio son Qoricocha (Qc), Tambomachay (Tbc), Cusco (Cc), Casacunca (Csc), San Juan de Quihuares (SJQ) y Paruro (Pr). Estas fallas se han agrupado por sus orientaciones preferenciales Csc, SJQ y $\operatorname{Pr}\left(150^{\circ}\right)$; Tbc y Qc $\left(122^{\circ}\right)$ y $\operatorname{Cc}\left(112^{\circ}\right)$.

\section{MÉTODOS}

\subsection{Adquisición de datos}

Se utilizó un modelo de elevación digital (DEM) con una resolución de $12.5 \mathrm{~m}$ ALOS PALSAR (Figura 3A) obtenido de la Agencia de Exploración Aeroespacial de Japón (JAXA), la cual se descargó de manera gratuita del sitio web de la NASA, para realizar los distintos procesos e identificar lineamientos estructurales digitales y estructuras geológicas (Fallas), así también la imagen RASTER se proyectó en el Sistema de coordenadas Universal Transversal de Mercator WGS-84 UTM Zona 18S.

\subsection{Sombreamiento multidireccional}

Para determinar los lineamentos usando el sombreado multidireccional, se toma como base el modelo de elevación digital (DEM) y la metodología de (Mark, 1992). Se genera una iluminación en diferentes posiciones para obtener una imagen con una iluminación homogénea, para realizar este mapa de sombreamiento multidireccional (Figura 3B) se usó el software QGIS 3.4.12. El procedimiento es detallado en la tabla 2.

\subsection{Sombreamiento con variación de la luz cada $30^{\circ}$ de $0^{\circ}$ a $330^{\circ}$}

Para determinar lineamientos, a partir del DEM se simula un efecto de iluminación desde un punto base con valores de azimut y altitud de iluminación, es por ello que se hacen cambios en el azimut solar cada 30 grados generándose así 12 imágenes con diferentes ángulos $\left(0^{\circ}, 30^{\circ}, 60^{\circ}, 90^{\circ}\right.$, $120^{\circ}, 150^{\circ}, 180^{\circ}, 210^{\circ}, 240^{\circ}, 270^{\circ}, 300^{\circ}$ y $\left.330^{\circ}\right)$. Para generar estas imágenes de sombreado (Figura 4A) se usó el software QGIS 3.4.12. El procedimiento es detallado en la tabla 2 .

\subsection{Sombras combinadas}

Para extraer lineamientos con diferentes orientaciones, a partir del DEM, se crearon doce imágenes ráster sombreadas para cada DEM usando la herramienta de Mapa de sombras (Hillshade) en QGIS 3.4.12. La primera imagen en relieve sombreada se iluminó desde el norte (es decir, azimut solar $0^{\circ}$ ), con una inclinación solar de $45^{\circ}$ (QGIS predeterminado); para las otras once imágenes en relieve, se utilizó una inclinación solar idéntica junto con otras once direcciones de iluminación, que incluyen: $30^{\circ}, 60^{\circ}, 90^{\circ}, 120^{\circ}, 150^{\circ}, 180^{\circ}, 210^{\circ}, 240^{\circ}, 270^{\circ}, 300^{\circ} \mathrm{y}$ $330^{\circ}$. Los valores de iluminación e inclinación del azimut tienden a ocultar o resaltar las características morfológicas en una imagen sombreada, dependiendo de su orientación con respecto a la fuente de luz simulada (Solano et al.,

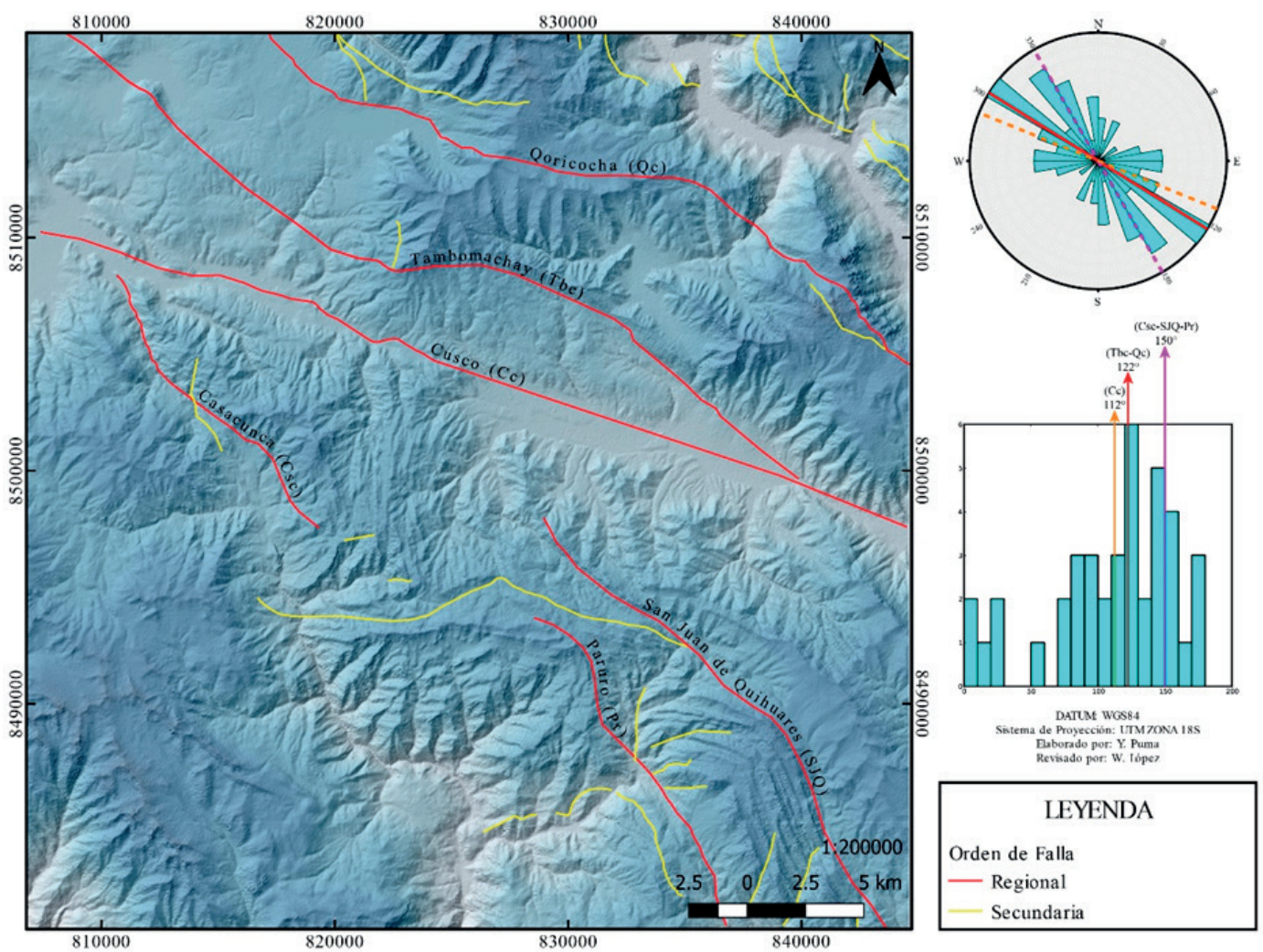

Figura 2. Mapa de Fallas cartografiadas por INGEMMET (Carlotto Caillaux et al., 1996), (Carlotto Caillaux et al., 2011) 

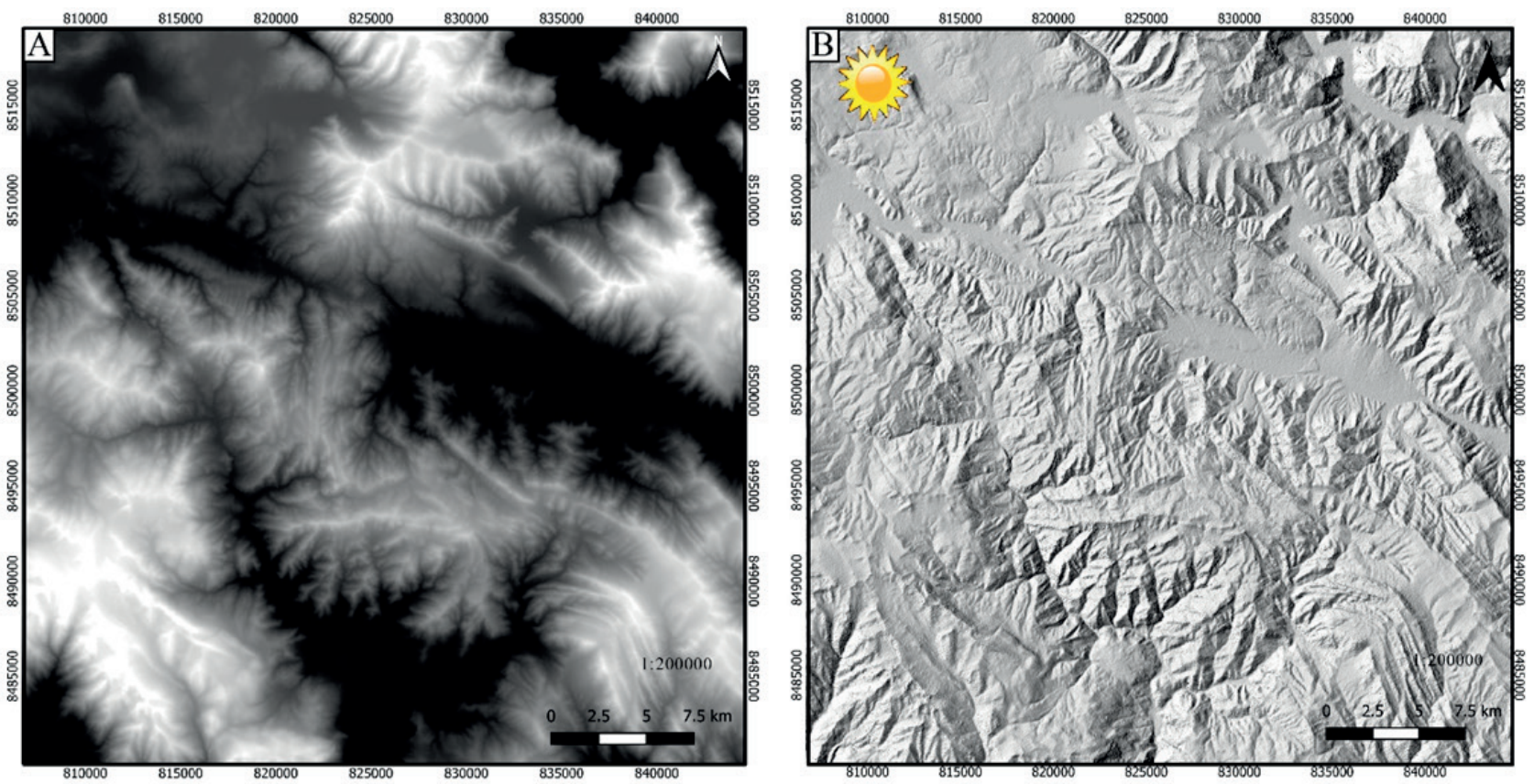

Figura 3. Modelo de elevación digital (A) y mapa de sombreamiento multidireccional (B).

2020); (Radaideh et al., 2016). Estas imágenes combinadas resaltan lineamientos y características topográficas con una variedad de direcciones, que no sería visible si solo se usara una imagen sombreada. Las primeras seis imágenes en relieve sombreadas fueron superpuestas y combinadas en el software QGIS 3.4.12. para producir una imagen con direcciones de iluminación múltiple $\left(0^{\circ}, 30^{\circ}, 60^{\circ}, 90^{\circ}\right.$, $120^{\circ}$ y $150^{\circ}$-Combinación 1 ), y las seis imágenes restantes $\left(180^{\circ}, 210^{\circ}, 240^{\circ}, 270^{\circ}, 300^{\circ}\right.$ y $330^{\circ}$ - Combinación 2) se procesaron de la misma manera (Figura 4By 4C). El procedimiento es detallado en la tabla 2.

\subsection{Mapa de Imagen de Relieve Rojo (RRIM)}

Utilizamos un DEM como mapa base para los mapas derivados que se realizan con el fin de identificar posibles fallas.

El RRIM es una multiplicación de tres capas de elementos de relieve, pendiente topográfica, apertura positiva y apertura negativa. La apertura positiva y negativa fue definida por (Yokoyama et al., 2002). La apertura negativa representa la concavidad de la superficie como valles y la apertura positiva representa la convexidad de la superficie como crestas; para generar estas imágenes de apertura positiva y negativa se usó el software SAGA GIS 7.9.0.

La parte principal de RRIM es la definición de un nuevo parámetro calculado a partir de dos parámetros de apertura como a continuación: $I=\left(O_{p}-O_{n}\right) / 2$

Donde $O_{p}$ es apertura positiva, $O_{n}$ es apertura negativa. $O_{p}$ y $O_{n}$ son esquemáticamente para valores menores de 90 grados. I es un límite radial de cálculo para puntos elegidos en un DEM y generado en el software SAGA GIS 7.9.0. El parámetro anterior elimina de manera eficiente la dependencia de la dirección de la luz incidente, que expresa convexidad y concavidad al mismo tiempo.
En este método de visualización, la fusión de la pendiente topográfica generada en el software SAGA GIS 7.9.0 y la tasa de apertura crea el RRIM, está superposición de imágenes para crear dicha visualización se genera en el software QGIS 3.4.12. Según (Chiba et al., 2008) el color rojo tiene el tono más rico para los ojos humanos, especialmente en el espacio de color orientado a la computadora. Cabe señalar que RRIM representa de manera efectiva una característica terrestre a gran escala, así como una estructura fina al mismo tiempo, en una amplia variedad de situaciones topográficas, pero no incluye información sobre la elevación y dirección de la pendiente. Pero se puede hacer uso de un mapa de contornos que complementaria esta información y la haría más eficiente (Özpolat et al., 2020) como se observa en la Figura 5, donde muestra el procedimiento de producción de RRIM y sus elementos de relieve.

Así también esta Figura 5 aparte de dar a conocer los pasos de producción del Mapa de imagen de Relieve Rojo (RRIM), muestra de manera puntual un diagrama de color del método RRIM. En donde la pendiente topográfica tendrá el valor cromático de rojo (eje y) y $\left(O_{p}-O_{n}\right) / 2$ se muestra como brillo (eje x). Como resultado, la parte superior de las crestas están de color blanco, la parte inferior de los valles de color negro, las pendientes pronunciadas tienen un rojo brillante y las superficies planas se muestran en gris en RRIM, el RRIM representa eficazmente la estructura topográfica fina incluso en la superficie plana (Chiba et al., 2008); (Chiba \& Hasi, 2016). El procedimiento es detallado en la tabla 2 .

\subsection{Obtención y procesamiento de lineamientos estructurales}

Los lineamientos estructurales se generaron de forma manual y la dirección de los lineamientos estructurales se 


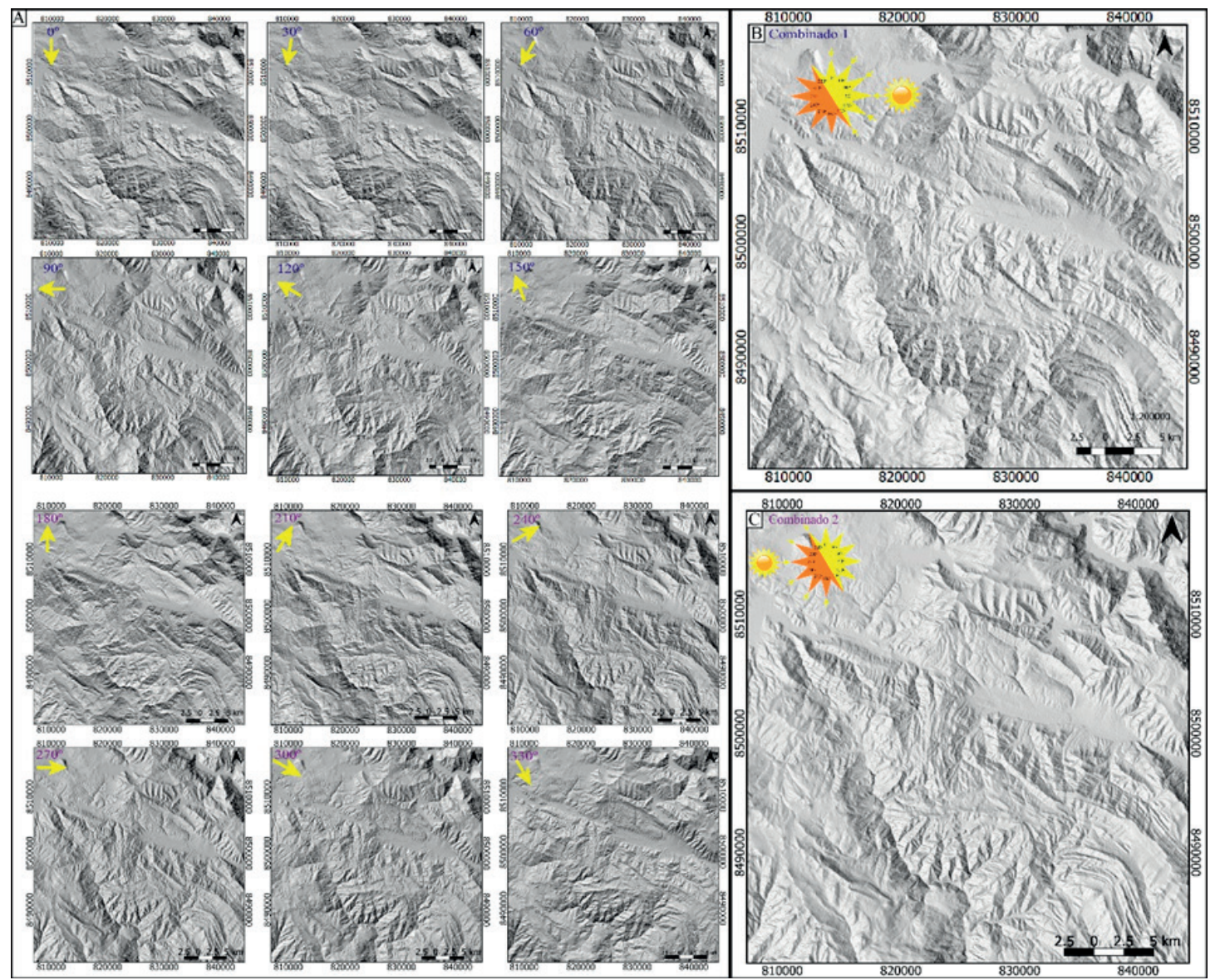

Figura 4. Las doce imágenes ráster sombreadas con una caída de luz constante de $45^{\circ}$ y variación de azimut de luz cada $30^{\circ}$ (A). Imágenes con iluminación múltiple que resultó de la combinación de imágenes sombreadas: la combinación 1 incluye imágenes sombreadas de $0^{\circ}-150^{\circ}$ (B) y la combinación 2 incluye imágenes sombreadas de $180^{\circ}$ a $330^{\circ}(\mathrm{C})$.

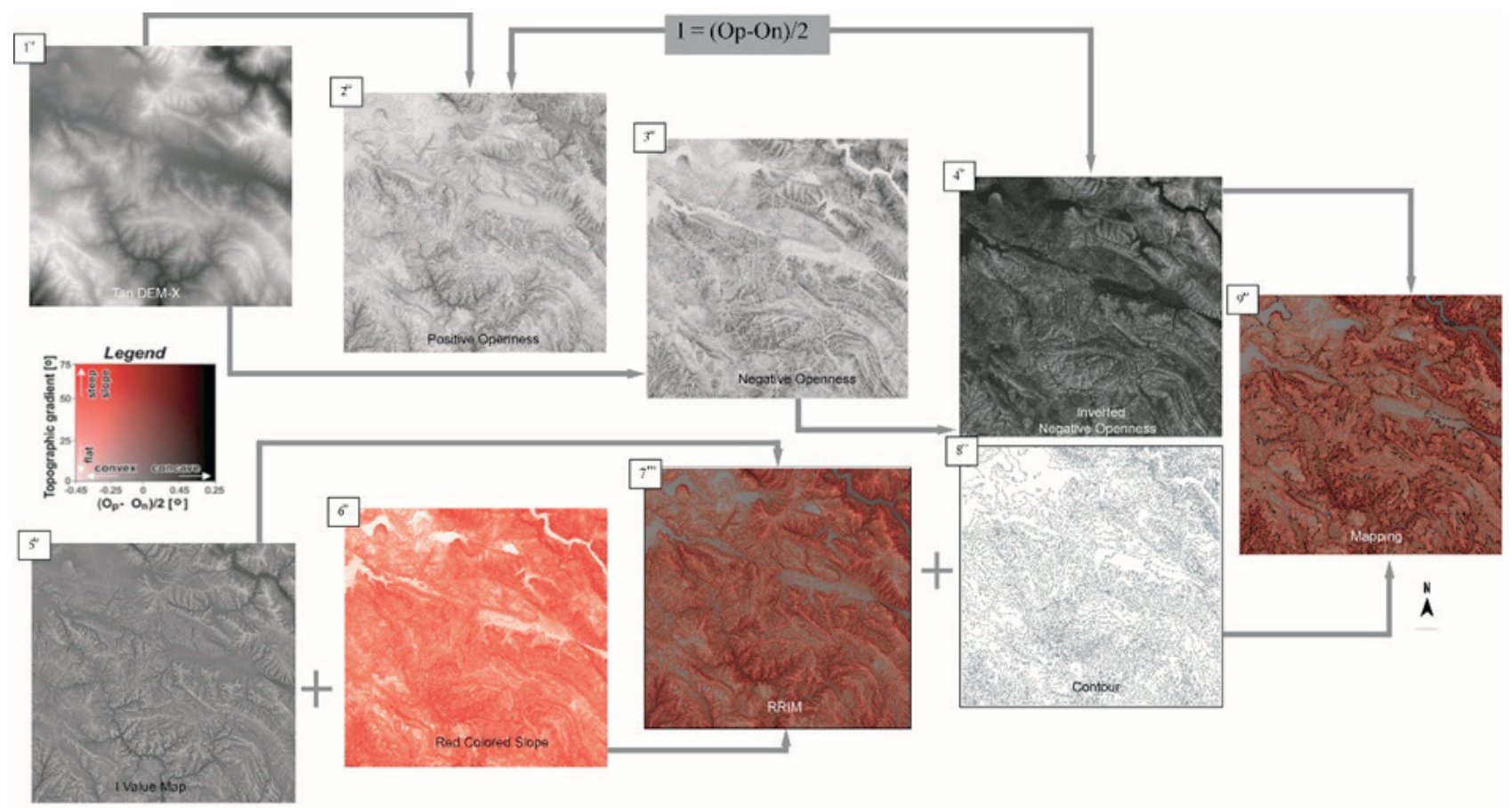

Figura 5. Pasos de producción de Red Relief Image Map (RRIM) propuestos por (Chiba et al., 2008). 
determinan usando la calculadora de campo en el software QGIS 3.4.12 con la siguiente formula:

“degrees(azimuth(start_point(\$geometry), end_point(\$geometry)))"

Con las direcciones de los lineamientos estructurales se realizaron gráficos de rosetas, haciendo uso del software Stereonet 11.3.0 (Allmendinger et al., 2012) y gráficos de histogramas, haciendo uso del software OpenStereo 0.1 (Grohmann et al., 2011); y a partir de estos gráficos se determinaron las tendencias generales de los lineamientos.

\section{RESULTADOS}

\subsection{Sombreamiento Multidireccional}

Se lograron determinar 745 lineamentos estructurales y 4 tendencias (Figura 6). Estas tendencias son las siguientes:
- $\quad$ Tendencia $1(\mathrm{~T} 1)$ es $024^{\circ}$.

- $\quad$ Tendencia 2 (T2) es $137^{\circ}$.

- $\quad$ Tendencia 3 (T3) es $174^{\circ}$.

- Tendencia 4 (T4) es $062^{\circ}$.

3.2. Sombreamiento con variación de la luz cada $30^{\circ}$ de $0^{\circ}$ a $360^{\circ}$

Se lograron determinar 1173 lineamentos estructurales y 3 tendencias (Figura 7). Estas tendencias son las siguientes:

- $\quad$ Tendencia $1(\mathrm{~T} 1)$ es $005^{\circ}$.

- Tendencia 2 (T2) es $133^{\circ}$.

- Tendencia 3 (T3) es $050^{\circ}$.

Tabla 2. Procedimientos para realizar las técnicas de realce de relieve en este estudio

\begin{tabular}{|c|c|c|}
\hline Método & Determinar & Procedimiento \\
\hline $\begin{array}{l}\text { Sombreamiento } \\
\text { multidireccional }\end{array}$ & Mapa de sombras Multidireccional (Hillshade) & $\begin{array}{l}\text { Q Gis: Raster--- Análisis-- MDT (Modelos de Terreno)-Hillshade } \\
\text { (Multidireccional). }\end{array}$ \\
\hline $\begin{array}{l}\text { Sombreamiento con variación } \\
\text { de la luz cada } 30^{\circ} \text { de } 0^{\circ} \text { a } 330^{\circ}\end{array}$ & Mapa de Sombras (Hillshade) & Q Gis: Raster--- Análisis-- MDT (Modelos de Terreno)-Hillshade (Cada $30^{\circ}$ ). \\
\hline Sombras combinadas & $\begin{array}{l}\text { Combinado } 1\left(0^{\circ}-30^{\circ}-60^{\circ}-90^{\circ}-120^{\circ}-150^{\circ}\right) \\
\text { Combinado } 2\left(180^{\circ}-210^{\circ}-240^{\circ}-270^{\circ}-300^{\circ}-330^{\circ}\right)\end{array}$ & Q Gis: (Caja de herramientas---SAGA--Raster tools- Mosaic raster layers) \\
\hline \multirow{3}{*}{$\begin{array}{l}\text { Mapa de Imagen de Relieve } \\
\text { Rojo (RRIM) }\end{array}$} & Apertura Positiva y Negativa & $\begin{array}{l}\text { SAGA GIS: (Terrain Analysis-- Lighting, Visibility- Topographic Openness). } \\
\text { SAGA GIS: I Mapa de valor (Grid--Calculus-Grid Calculator). }\end{array}$ \\
\hline & Pendientes & $\begin{array}{l}\text { SAGA GIS: (Terrain Analysis--Morphometry- Slope, Aspect, Curvature). } \\
\text { SAGA GIS: Factor de Escala (Grid--Filter-Resapling Filter). }\end{array}$ \\
\hline & Curvas de Nivel & Q gis (Raster--extracción-curvas de nivel). \\
\hline
\end{tabular}
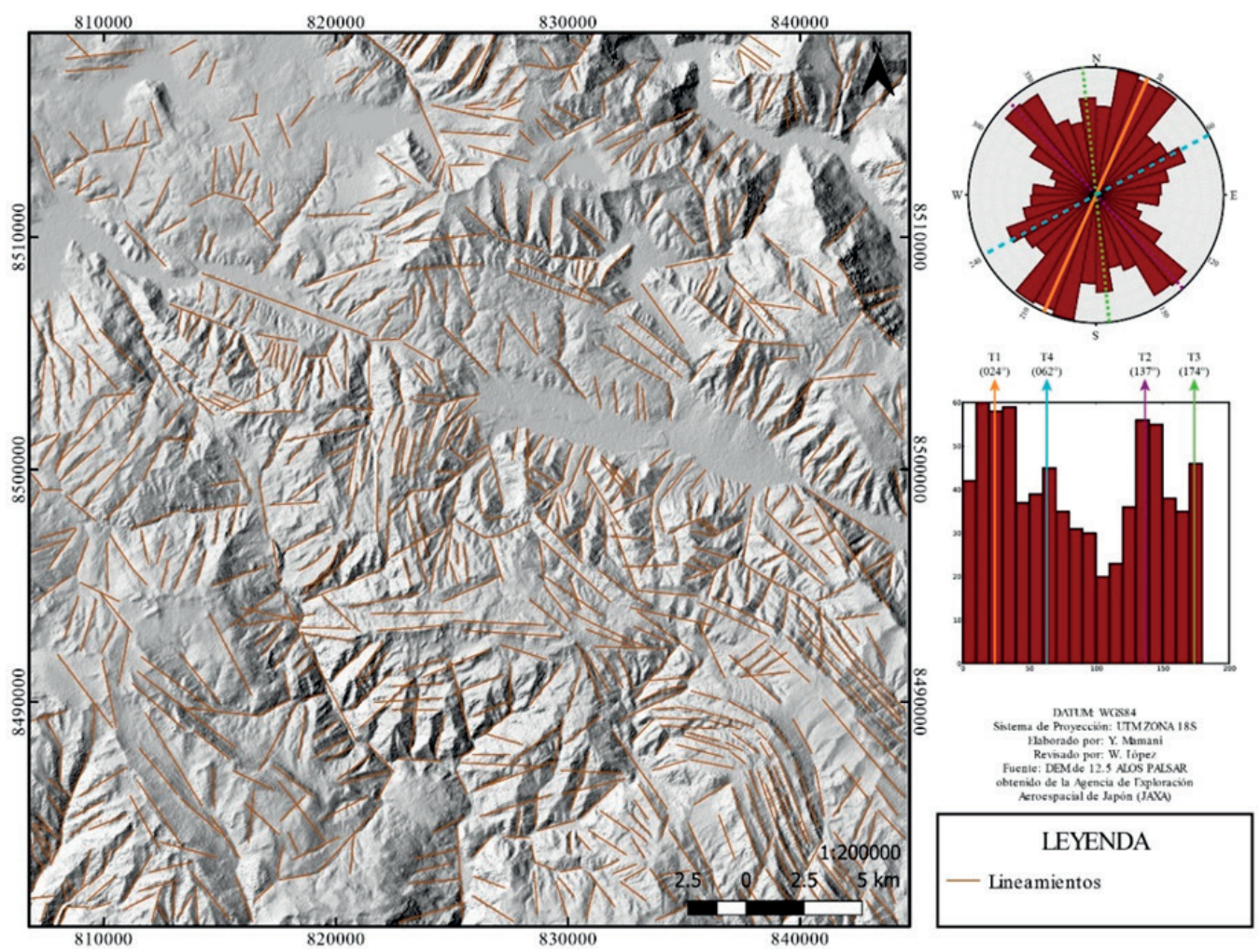

Figura 6. Lineamientos determinados a partir de un Mapa de sombras Multidireccional. Los gráficos de la derecha muestran las tendencias $\mathrm{T} 1: 024^{\circ}, \mathrm{T} 2: 137^{\circ}, \mathrm{T} 3: 174^{\circ}, \mathrm{T} 4: 062^{\circ}$. 


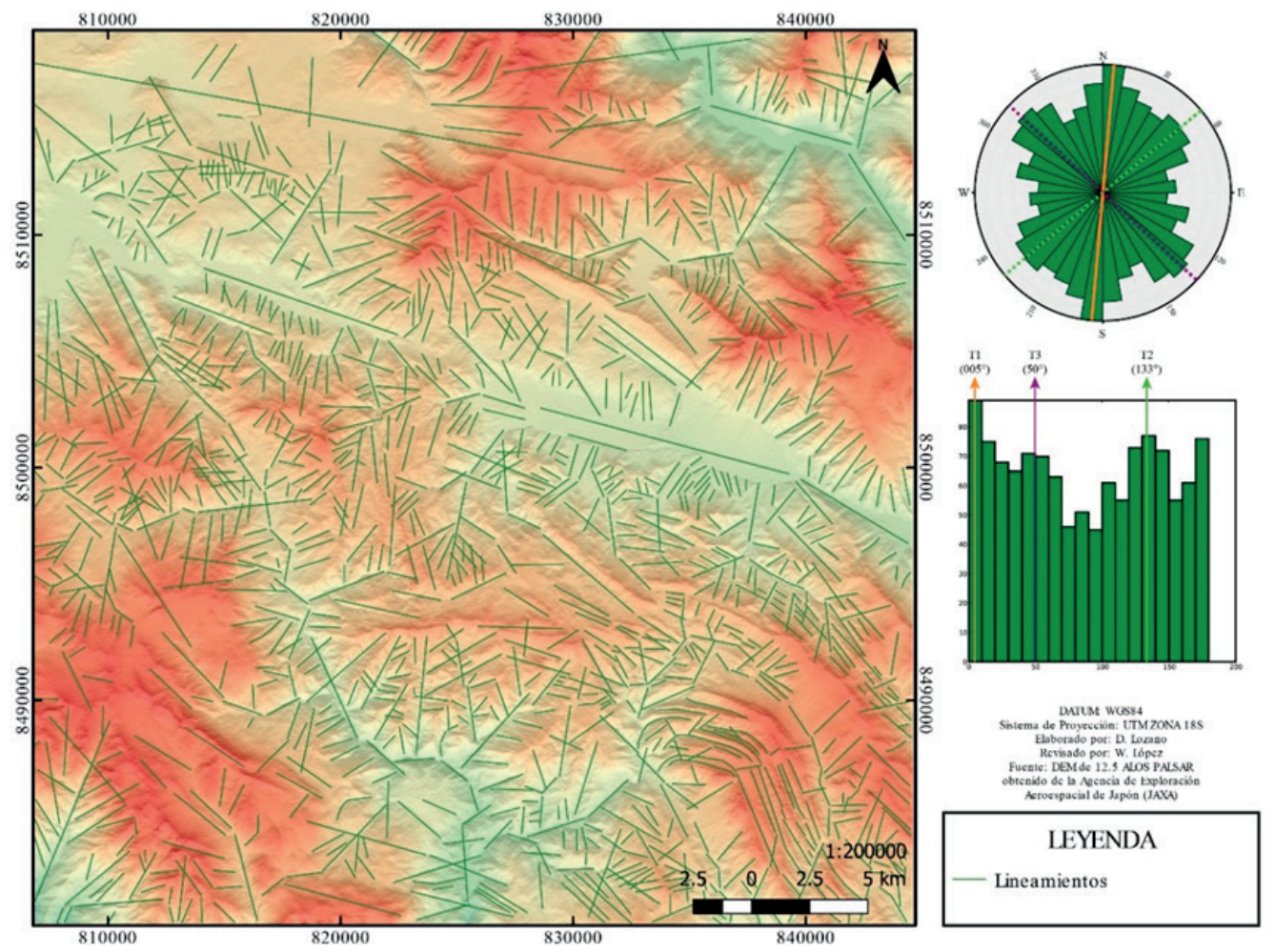

Figura 7. Lineamientos determinados a partir de un Mapa de sombras con variación de la luz cada $30^{\circ}$ de $0^{\circ}$ a $360^{\circ}$. Los gráficos de la derecha muestran las tendencias T1: $005^{\circ}, \mathrm{T} 2: 133^{\circ}, \mathrm{T} 3: 050^{\circ}$.

3.3. Sombreamiento Combinado $1\left(0^{\circ}, 30^{\circ}, 60^{\circ}\right.$, $90^{\circ}, 120^{\circ}$ y $\left.150^{\circ}\right)$ y Combinado $2\left(180^{\circ}, 210^{\circ}\right.$, $240^{\circ}, 270^{\circ}, 300^{\circ}$ y $\left.330^{\circ}\right)$

Del combinado 1 (C1) se logró determinar 736 lineamientos estructurales y 4 tendencias (Figura 8). Estas tendencias son las siguientes:

- Tendencia 1 (T1) es $113^{\circ}$.

- Tendencia 2 (T2) es $153^{\circ}$.

- $\quad$ Tendencia 3 (T3) es $035^{\circ}$.

- $\quad$ Tendencia 4 (T4) es $010^{\circ}$.

Del combinado 2 (C2) se logró determinar 749 lineamientos estructurales y 4 tendencias (Figura 9). Estas tendencias son las siguientes:

- Tendencia 1 (T1) es $000^{\circ}$.

- $\quad$ Tendencia 2 (T2) es $147^{\circ}$.

- $\quad$ Tendencia 3 (T3) es $113^{\circ}$.

- $\quad$ Tendencia 4 (T4) es $035^{\circ}$.

\subsection{Mapa de Imagen en Relieve Rojo (RRIM)}

En la zona de estudio el INGEMMET (Instituto Geológico, Minero y Metalúrgico), ha cartografiado 42 fallas y usando esta metodología se reconocieron 97 posibles fallas, siendo en total 139 estructuras geológicas, se determinaron 4 tendencias (Figura 10):

- $\quad$ Tendencia 1 (T1) es $148^{\circ}$.

- $\quad$ Tendencia 2 (T2) es $122^{\circ}$.

- $\quad$ Tendencia 3 (T3) es $094^{\circ}$.

- $\quad$ Tendencia 4 (T4) es $055^{\circ}$.

\section{DISCUSIONES}

En la figura $11 \mathrm{~A}$ se muestra el gráfico de rosetas e histograma de las fallas cartografiadas por INGEMMET, donde se resalta las tendencias de las estructuras regionales principales y es la información base sobre el cual parte nuestro trabajo.

La obtención de los lineamientos estructurales por la técnica del sombreamiento multidireccional (Figura 11C) refleja una tendencia promedio de estructuras regionales en la zona de estudio como son: T2 $\left(137^{\circ}\right)$ respecto a las fallas regionales Cusco $\left(112^{\circ}\right)$, Tambomachay y Qoricocha $\left(122^{\circ}\right)$, y Casacunca, San Juan de Quihuares y Paruro $\left(150^{\circ}\right)$. Se lograron también reconocer tres tendencias adicionales T1 $\left(024^{\circ}\right), \mathrm{T} 3\left(062^{\circ}\right)$ y $\mathrm{T} 4\left(174^{\circ}\right)$, las cuales indican que nos resalta el promedio de las estructuras regionales y se determinan otras estructuras que posiblemente son secundarias en nuestra zona de estudio. 

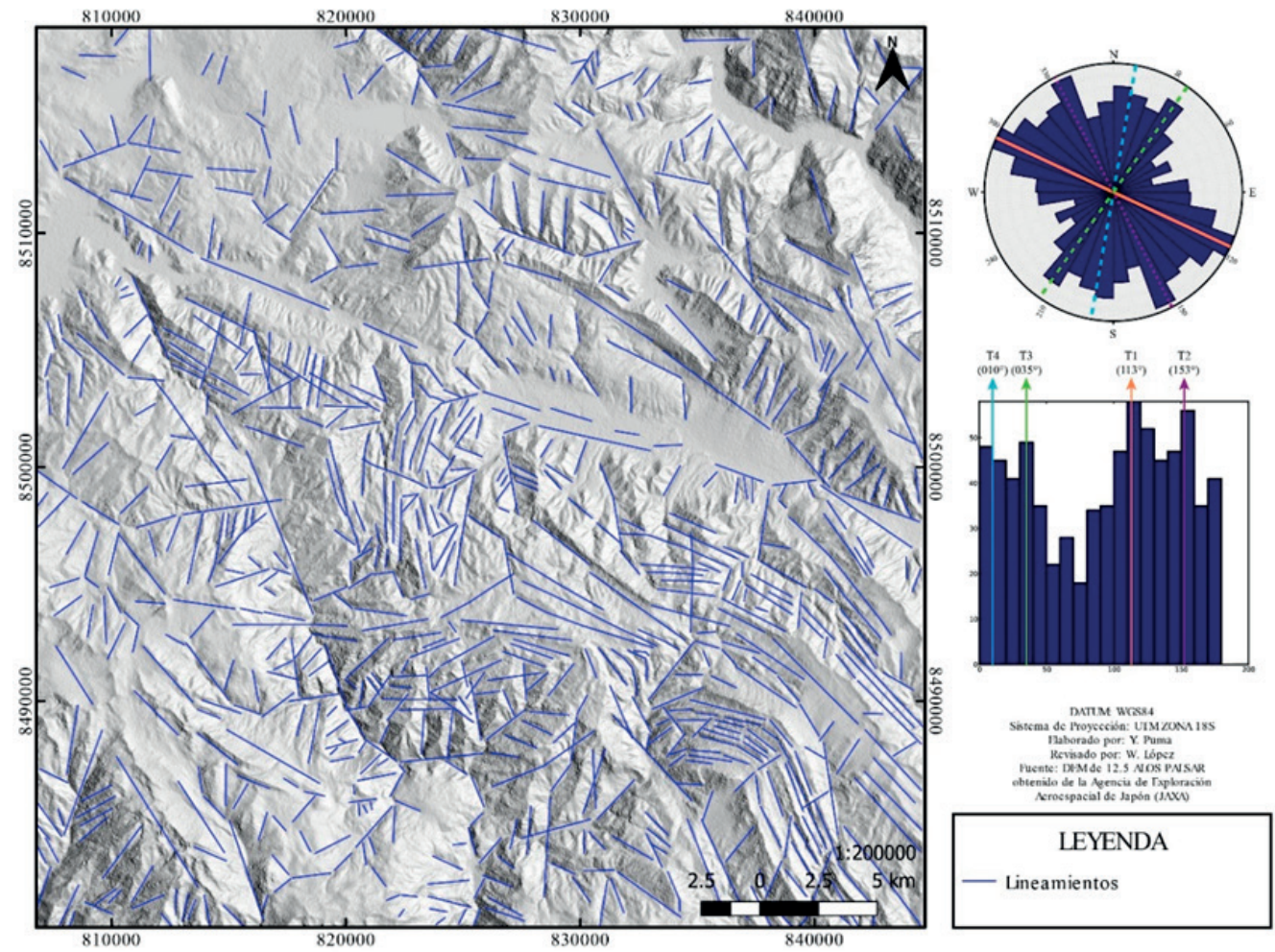

Figura 8. Lineamientos determinados a partir de un Mapa de sombras "Combinado $1^{\prime \prime}\left(0^{\circ}, 30^{\circ}, 60^{\circ}, 90^{\circ}, 120^{\circ}\right.$ y $\left.150^{\circ}\right)$. Los gráficos de la derecha muestran las tendencias T1: $113^{\circ}, \mathrm{T} 2: 153^{\circ}, \mathrm{T} 3: 035^{\circ}, \mathrm{T} 4: 010^{\circ}$.

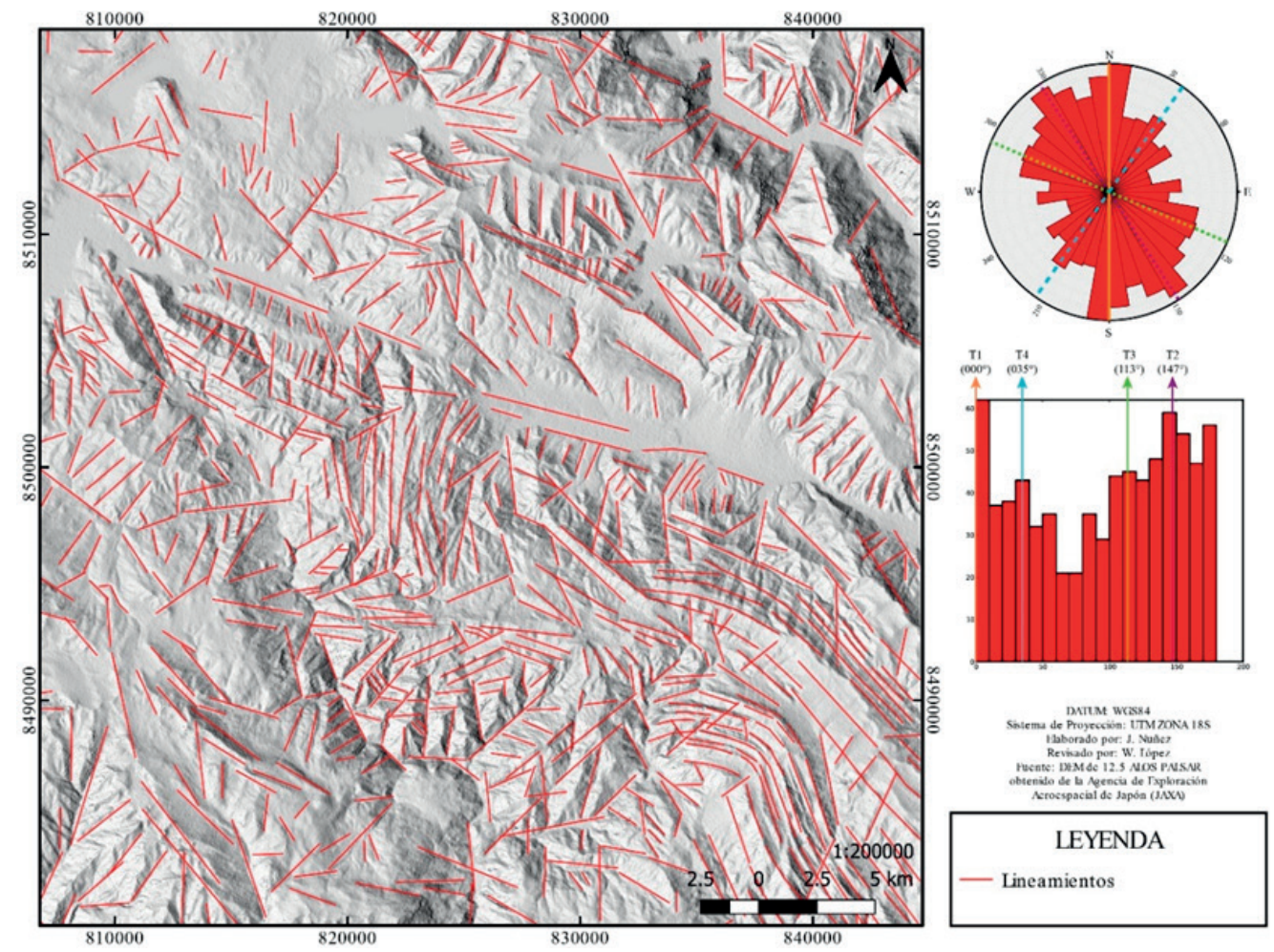

Figura 9. Lineamientos determinados a partir de un Mapa de sombras "Combinado $2^{\prime \prime}\left(180^{\circ}, 210^{\circ}, 240^{\circ}, 270^{\circ}, 300^{\circ}\right.$ y $330^{\circ}$ ). Los gráficos de la derecha muestran las tendencias $\mathrm{T} 1: 000^{\circ}, \mathrm{T} 2: 147^{\circ}, \mathrm{T} 3: 113^{\circ}, \mathrm{T} 4: 035^{\circ}$. 


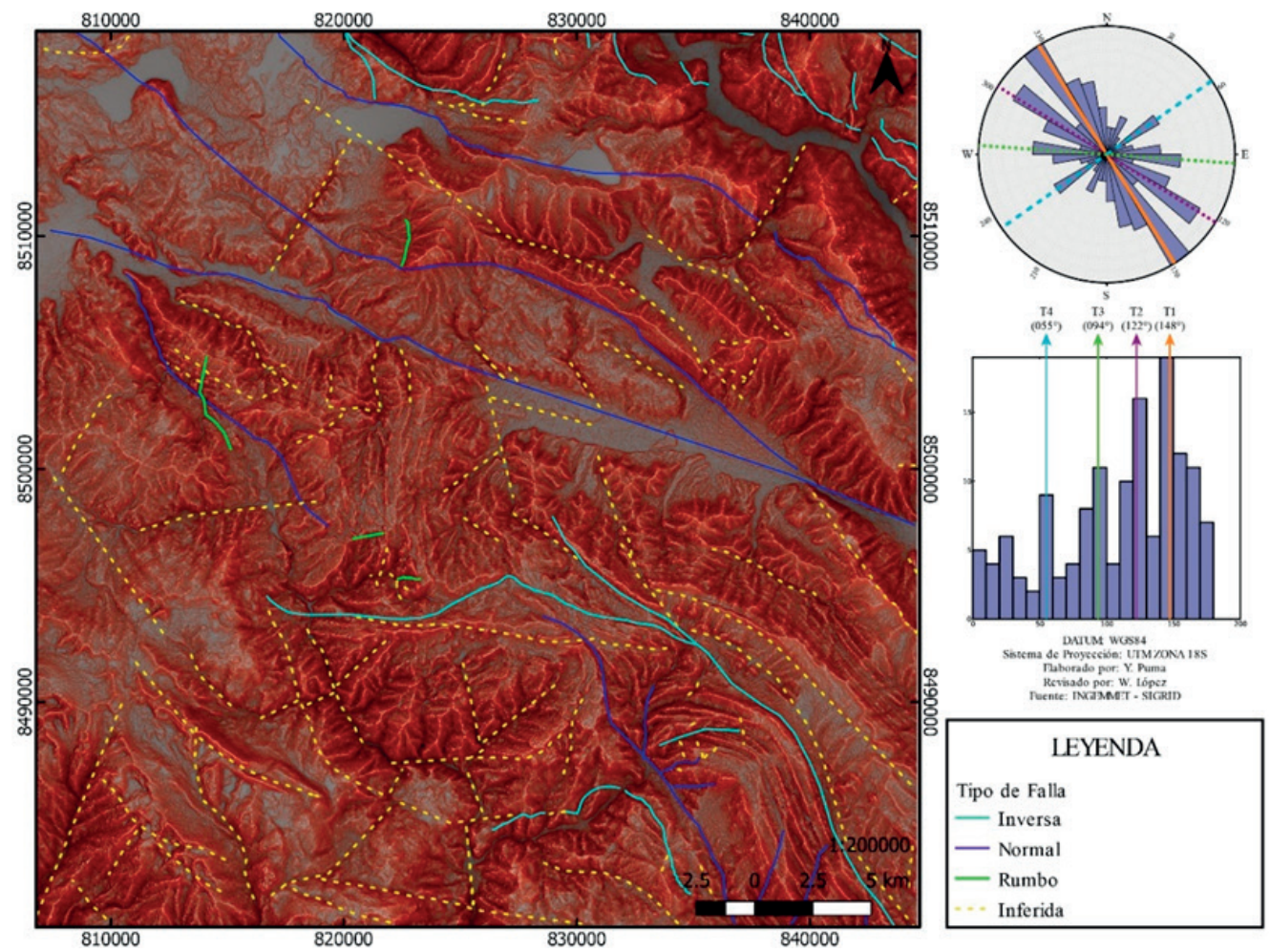

Figura 10. Fallas inferidas determinadas a partir de un Mapa de Imagen en Relieve Rojo. Los gráficos de la derecha muestran las tendencias T1: $148^{\circ}, \mathrm{T} 2: 122^{\circ}, \mathrm{T} 3: 094^{\circ}, \mathrm{T} 4: 055^{\circ}$.

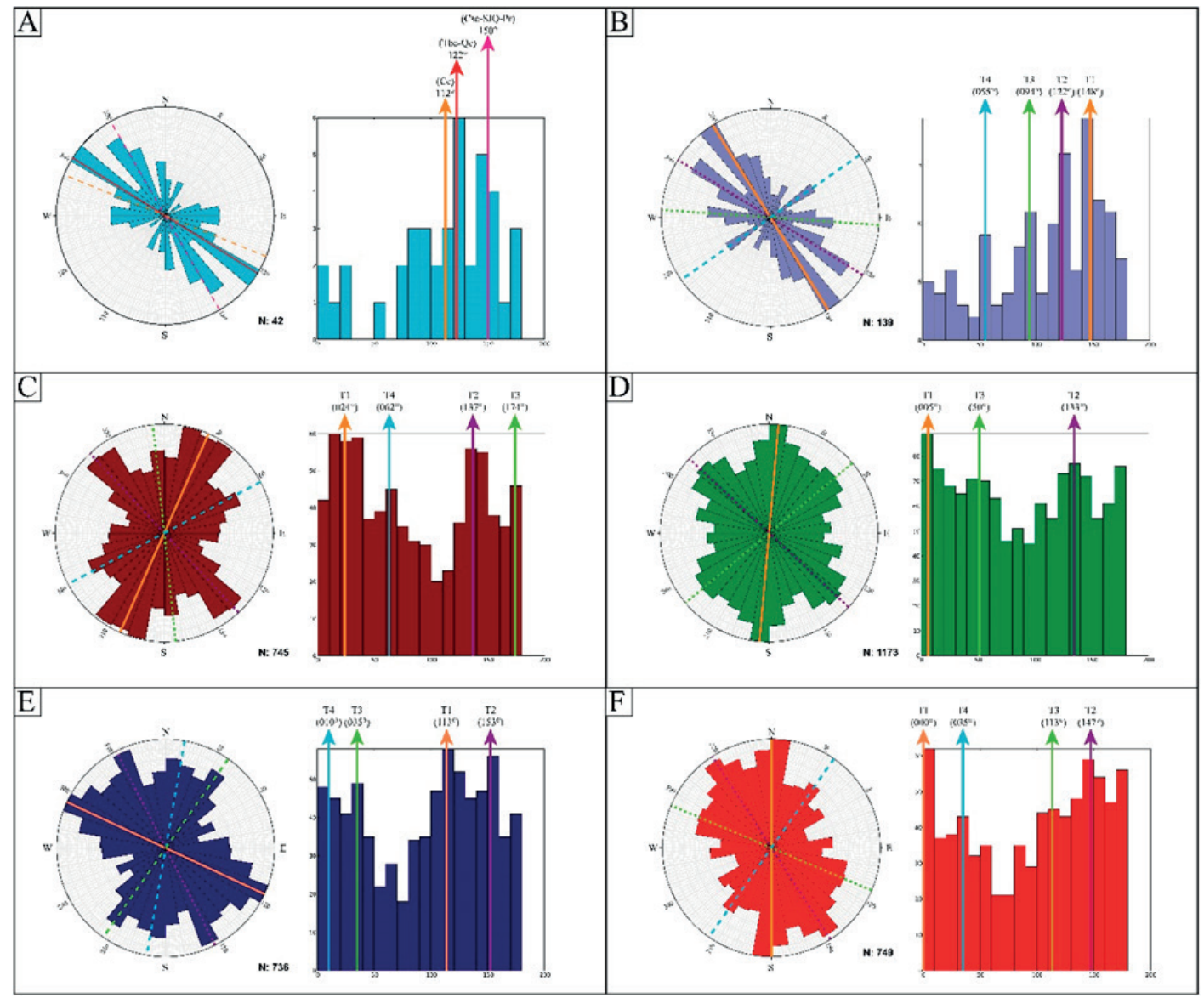

Figura 11. Gráficos de rosetas e histogramas obtenido de las fallas cartografiadas por INGEMMET (A); RRIM (B); sombreamiento multidireccional (C); sombreamiento cada $30^{\circ}$ de $0^{\circ}$ a $330^{\circ}$ (D); sombreamiento combinado 1 (E) y combinado $2(\mathrm{~F})$. 
La obtención de los lineamientos estructurales por la técnica de sombreamiento por variación de la luz cada $30^{\circ}$ de $0^{\circ}$ a $330^{\circ}$ (Figura 11D) refleja una tendencia promedio de estructuras regionales en la zona de estudio como son: $\mathrm{T} 2\left(133^{\circ}\right)$ respecto a las fallas regionales Cusco $\left(112^{\circ}\right)$, Tambomachay y Qoricocha $\left(122^{\circ}\right)$, y Casacunca, San Juan de Quihuares y Paruro $\left(150^{\circ}\right)$. Se lograron también reconocer dos tendencias adicionales $\mathrm{T} 1\left(005^{\circ}\right)$ y $\mathrm{T} 3$ $\left(050^{\circ}\right)$, las cuales indican que nos resalta el promedio de las estructuras regionales y se determinan otras estructuras que posiblemente son secundarias en nuestra zona de estudio.

La obtención de los lineamientos estructurales por la técnica de sombras combinadas C1 (Figura 11E) y C2 (Figura $11 \mathrm{~F})$ son muy similares en tendencias, pero no en la cantidad de datos por tendencia, $\mathrm{T} 1\left(113^{\circ}\right)$ de $\mathrm{C} 1$ es equivalente a $\mathrm{T} 3$ $\left(113^{\circ}\right)$ de $\mathrm{C} 2, \mathrm{~T} 2\left(153^{\circ}\right)$ de $\mathrm{C} 1$ es equivalente a T2 $\left(147^{\circ}\right)$ de $\mathrm{C} 2$, $\mathrm{T} 3\left(035^{\circ}\right)$ de $\mathrm{C} 1$ es equivalente a $\mathrm{T} 4\left(035^{\circ}\right)$ de $\mathrm{C} 2$ y T4 $\left(010^{\circ}\right)$ de $\mathrm{C} 1$ es equivalente a T1 $\left(001^{\circ}\right)$. Además, T1 $\left(113^{\circ}\right)$ de $\mathrm{C} 1$ y $\mathrm{T} 3\left(113^{\circ}\right)$ de $\mathrm{C} 2$ es equivalente a la falla regional Cusco $\left(112^{\circ}\right)$; $22\left(153^{\circ}\right)$ de $\mathrm{C} 1$ y T2 $\left(147^{\circ}\right)$ de $\mathrm{C} 2$ es equivalente a las fallas regionales Casacunca, San Juan de Quihuares y Paruro $\left(150^{\circ}\right)$, lo que nos resalta de una manera confiable las estructuras regionales y se determinan otras estructuras que posiblemente son secundarias en nuestra zona de estudio.

El realce de estructuras geológicas por el método RRIM (Figura 11B) resalta tanto en cantidad y tendencia las fallas regionales, T1 $\left(148^{\circ}\right)$ es equivalente a las fallas regionales Casacunca, San Juan de Quihuares y Paruro (150 ); T2 $\left(122^{\circ}\right)$ es equivalente a las fallas regionales Tambomachay y Qoricocha $\left(122^{\circ}\right)$. Además, se reconocieron dos posibles tendencias de fallas T3 $\left(094^{\circ}\right)$ y T4 $\left(055^{\circ}\right)$.

Se lograron encontrar 6 tendencias generales (Tabla 3 y Figura 12), de las cuales las fallas regionales son las que se pueden observar en todas las tendencias obtenidas en los
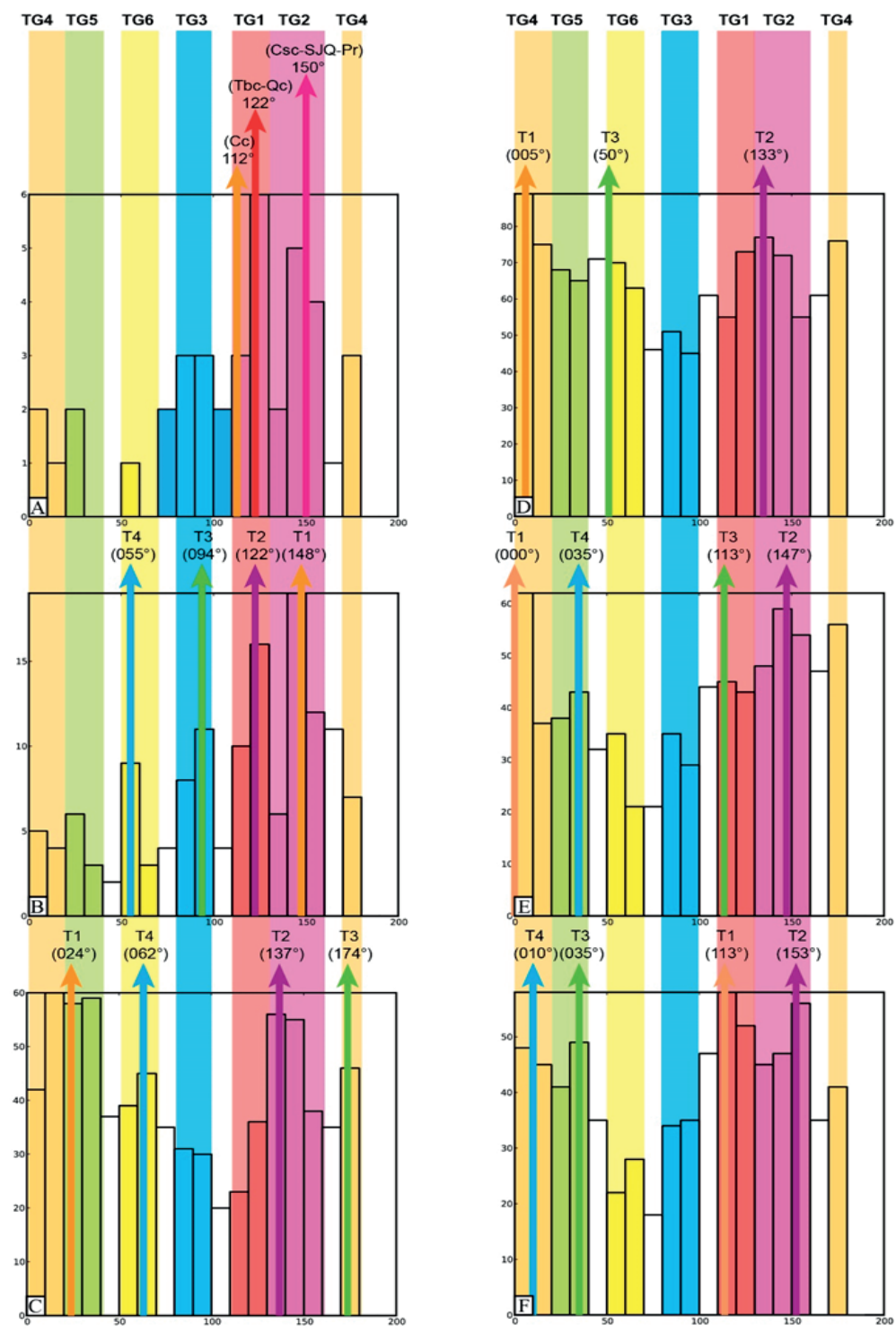

Figura 12. Histogramas de los diferentes métodos y su relación con las tendencias generales. INGEMMET (A); RRIM (B); sombreamiento multidireccional (C); sombreamiento cada $30^{\circ}$ de $0^{\circ}$ a $330^{\circ}(\mathrm{D})$; sombreamiento combinado 2 (E) y combinado 1 (F). 
diferentes procesos en $\mathrm{TG} 1\left(100^{\circ}-130^{\circ}\right)$ y TG2 $\left(130^{\circ}-160^{\circ}\right)$, La tendencia general TG3 $\left(080^{\circ}-100^{\circ}\right)$ solo se observa en el RRIM y es importante porque nos resalta posibles fallas. La tendencia general TG4 $\left(170^{\circ}-180^{\circ} / 000^{\circ}-020^{\circ}\right)$ que es norte-sur se presenta en todos los métodos donde se obtuvieron los lineamientos estructurales. La tendencia TG5 $\left(020^{\circ}-040^{\circ}\right)$ se resalta en los métodos de lineamientos obtenidos como son: sombreamiento múltiple y sombras combinadas $(\mathrm{C} 1$ y $\mathrm{C} 2)$. La tendencia TG6 $\left(050^{\circ}-070^{\circ}\right)$ resalta las posibles fallas obtenidas de RRIM y estas a su vez se encuentran representadas en los lineamientos obtenidos por sombreamiento multidireccional y sombreamiento cada $30^{\circ}$ de $0^{\circ}$ a $330^{\circ}$.

Tabla 3. Tendencias generales y sus intervalos

\begin{tabular}{|cc}
\hline Tendencias generales & Intervalos \\
\hline TG1 & $110^{\circ}-130^{\circ}$ \\
TG2 & $130^{\circ}-160^{\circ}$ \\
TG3 & $080^{\circ}-100^{\circ}$ \\
TG4 & $170^{\circ}-180^{\circ} / 000^{\circ}-020^{\circ}$ \\
TG5 & $020^{\circ}-040^{\circ}$ \\
TG6 & $050^{\circ}-070^{\circ}$ \\
\hline
\end{tabular}

\section{CONCLUSIONES}

- Se utilizaron tres técnicas para identificar lineamientos estructurales: Sombreamiento multidireccional, sombreado con variación de la luz cada $30^{\circ}$ y sombras combinadas ( $\mathrm{C} 1$ y $\left.\mathrm{C} 2\right)$; mediante el uso de software libres y de código.

- Con el método RRIM, se han definido con mayor precisión fallas regionales y locales que identificó INGEMMET; así mismo se identificaron otras estructuras geológicas que posiblemente son fallas con tendencia TG3 $\left(130^{\circ}-160^{\circ}\right)$.

- En la zona de estudio se determinaron 6 tendencias generales: TG1 $\left(110^{\circ}-130^{\circ}\right), \mathrm{TG}^{\circ}\left(130^{\circ}-160^{\circ}\right)$, TG3 $\left(80^{\circ}-100^{\circ}\right)$, TG4 $\left(170^{\circ}-180^{\circ} / 0^{\circ} 20^{\circ}\right)$, TG5 $\left(20^{\circ}-40^{\circ}\right)$ y TG6 $\left(50^{\circ}-70^{\circ}\right)$.

- Los resultados obtenidos mediante los métodos utilizados se complementan y en todas las técnicas realizadas se pueden apreciar la tendencia de las fallas regionales (TG1 y TG2), pero donde mejor se representa las estructuras regionales es por el método de sombras combinadas ( $\mathrm{C} 1$ y $\mathrm{C} 2)$.

\section{AGRADECIMIENTOS}

Agradecemos a la Dra. Ana Ibis Despaigne y al Dr. Willy Gil Rodriguez por sus comentarios, recomendaciones y correcciones al manuscrito.

\section{REFERENCIAS}

Allmendinger,R.W.,Cardozo,N.C.,\&Fisher,D.(2012).Structural Geology Algorithms: Vectors and Tensors. Cambridge, UK, Cambridge University Press. https://books.google.com.
pe/books?hl=es\&lr=\&id=y4WalY4ZptAC\&oi=fnd\&pg $=$ PR5\&dq $=$ Allmendinger,+ R.W., + Cardozo, + N.C., + Fisher, + D. $+(2012) .+$ Structural+Geology+Algorithms:+Vectors + and+Tensors:+Cambridge, + UK,,+ Cambridge+University + Press,$+289+\mathrm{p} \% \mathrm{C} 3 \% \mathrm{~A} 1$ gs\&ots $=$ rdkVboxelr\&sig $=$ Stq $10 \mathrm{C}$ aOWYB3qY781krbMLqxj7A\#v=onepage \&q\&f=false

Benavente, C., Delgado, F., Taipe, E., Audin, L., \& Pari, W. (2013). Neotectónica y peligro sísmico en la región Cusco [Boletín C 55]. INGEMMET. Serie C: Geodinámica e Ingeniería Geológica; $\mathrm{N}^{\circ}$ 55. https://repositorio.ingemmet. gob.pe/handle/20.500.12544/296

Bruno de Olivera, D., da Silva Moreno, R., Justa de Miranda, D., da Silva Ribeiro, C., Carlos Sícoli Seoane, J., \& Limeira Melo, C. (2009). Elaboração de um mapa de lineamento estrutural e densidade de lineamento através de imagem SRTM , em uma área ao norte do rio Doce, ES. Simpósio Brasileiro de Sensoriamento Remoto, 4157-4163. http:// webhelp.esri.com/

Cabrera Nuñez Justo. (1988). Néotectonique et sismotectonique dans la Cordillère andine au niveau du changement de géométrie de la subduction: la région de Cuzco (Pérou). http://www.theses.fr/1988PA112234

Carlotto Caillaux, Víctor Santiago, Cárdenas Roque, José Dionicio, \& Carlier, G. (2011). Geología del cuadrángulo de Cusco, hoja 28-s, escala 1:50,000 - [Boletín A 138]. INGEMMET. Boletín, Serie A: Carta Geológica Nacional. https:// repositorio.ingemmet.gob.pe/handle/20.500.12544/99

Carlotto Caillaux, Víctor Santiago, Gil Rodriguez, Willy Fernando, Cárdenas Roque, José Dionicio, \& Chávez, R. (1996). Geología de los cuadrángulos de Urubamba y Calca. Hojas: 27-r y 27-s - [Boletín A 65]. INGEMMET. Boletín, Serie A: Carta Geológica Nacional. https:// repositorio.ingemmet.gob.pe/handle/20.500.12544/187

Chiba, T., \& Hasi, B. (2016). Ground surface visualization using red relief image map for a variety of map scales. The International Archives of the Photogrammetry, Remote Sensing and Spatial Information Sciences, XLI(B2), 393-397. https://doi.org/10.5194/isprsarchivesXLI-B2-393-2016

Chiba, T., Kaneta, S.-I., \& Suzuki, Y. (2008). Red relief image map: New visualization method for three dimensional data. The International Archives of the Photogrammetry. Sciences Remote Sensing and Spatial Information, 37(B2), 1071-1076. https://citeseerx.ist.psu.edu/viewdoc/ download?doi=10.1.1.644.2038\&rep=rep1\&type $=$ pdf

Grohmann, C. H., Campanha, G. A. C., \& Soares Junior, A. v. (2011). Openstereo: um programa livre e multiplata forma para análise de dados estruturais. Simp. Nac. Est. Tectônicos, 13, Campinas e Intern. Simp. on Tectonics, 7, Campinas. Anais VIII SNET, Campinas: SBG/NE, 26-28. http://www. gnu.org/

Mader, D. , \& Schenk, B. (2017). Using Free/Libre and Open Source Software in the Geological Sciences. Austrian Journal of Earth Sciences, 110(1), 142-161. https://www. univie.ac.at/ajes/archive/volume $110 \quad 1 /$ mader schenk ajes_110_1.pdf

Mark, R. K. (1992). Multidirectional, oblique-weighted, shadedrelief image of the Island of Hawaii. U.S. Geological Survey Open-File Report. https://pubs.er.usgs.gov/publication/ ofr 92422 
O’Leary, D. W. , Friedman, J. D. , \& Pohn, H. A. (1976) Lineament, linear, lineation: Some proposed new standards for old terms. GSA Bulletin. GeoScienceWorld, 87, 14631469. https://pubs.geoscienceworld.org/gsa/gsabulletin/ article/87/10/1463/201929/Lineament-linear-lineationSome-proposed-new

Özpolat, E. , Yıldırım, C. , \& Görüm, T. (2020). The Quaternary landforms of the Büyük Menderes Graben System: the southern Menderes Massif, western Anatolia, Turkey. Journal of Maps , 16(2), 405-419. https://www.tandfonline. com/doi/full/10.1080/17445647.2020.1764874

Radaideh, O. M. A., Grasemann, B., Melichar, R., \& Mosar, J. (2016). Detection and analysis of morphotectonic features utilizing satellite remote sensing and GIS: An example in SW Jordan. Geomorphology, 275, 58-79. https://doi. org/10.1016/j.geomorph.2016.09.033
Solano, J. D. , Despaigne, A. I. , \& Pearse, J. (2020). Morphotectonic Analysis of the Upper Guajira, Colombia. A GIS and Remote Sensing Approach. Preprints, 1, 1-32. https://www.preprints.org/manuscript/202010.0476/v1

Tzvetkov, J. (2018). Relief visualization techniques using free and open source GIS tools. Polish Cartographical Review, 50(2) 61-71. https://sciendo.com/article/10.2478/pcr-2018-0004

Yokoyama, R., Shlrasawa, M., \& Pike, R. J. (2002). Visualizing Topography by Openness: A New Application of Image Processing to Digital Elevation Models. Photogrammetric Engineering \& Remote Sensing , 68(3), 257-265. http://citeseerx.ist.psu.edu/viewdoc/ download?doi=10.1.1.451.9798\&rep=rep1\&type=pdf 